University of Minnesota Morris Digital Well

University of Minnesota Morris Digital Well

$11-28-2017$

\title{
Parenting and Motocross: The Whoops and Downs
}

Marissa E. Holst

University of Minnesota - Morris, meholst@morris.umn.edu

Follow this and additional works at: https://digitalcommons.morris.umn.edu/psych_facpubs

Part of the Child Psychology Commons, and the Sports Studies Commons

\section{Recommended Citation}

Holst, M.E. \& Stuhlsatz, G.L. (2017). Parenting and motocross: the whoops and downs. Journal of Amateur Sport, 3(3), 44-63.

This Article is brought to you for free and open access by the Faculty and Staff Scholarship at University of Minnesota Morris Digital Well. It has been accepted for inclusion in Psychology Publications by an authorized administrator of University of Minnesota Morris Digital Well. For more information, please contact skulann@morris.umn.edu. 


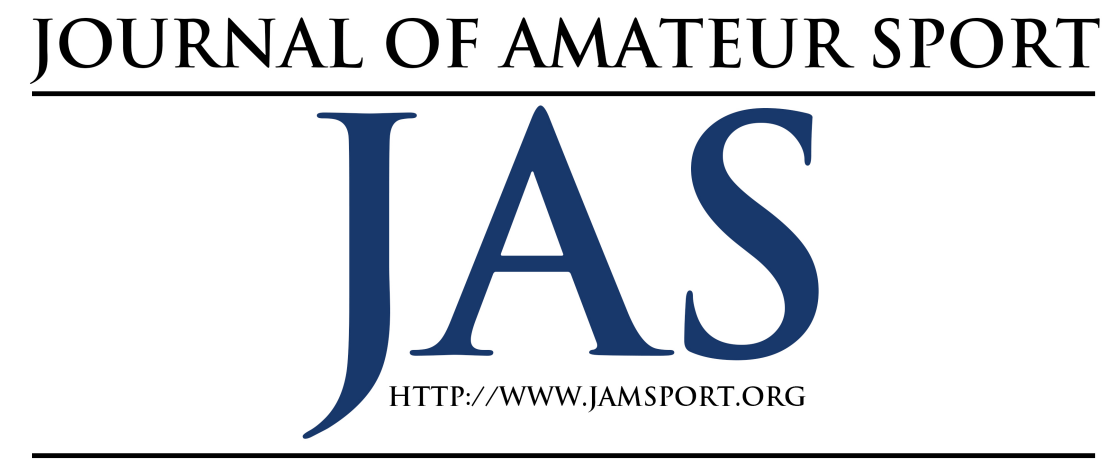

\title{
Parenting and Motocross: The Whoops and Downs
}

\author{
Marissa E. Holst ${ }^{1}$ \\ Greta L. Stuhlsatz ${ }^{2}$ \\ ${ }^{1}$ University of Minnesota-Morris \\ ${ }^{2}$ Iowa State University
}

Many studies address the influences of parenting and contextual factors on child development (Belsky, 1984). Although long-term contextual factors such as poverty and abuse have been shown to be associated with both parent and child behaviors (La Placa \& Corlyon, 2016; Salzinger et al, 2002), little research exists on the degree to which short-term situational contexts may affect child behavior. The goal of this study is to identify the influence of parenting behavior on child response after a competitive motocross race. Survey data was collected from 33 parents at several child/adolescent competitions held at a motocross track. First, results indicated that hostility exhibited by the trackside parent, or the parent that spends the most time with their child trackside, at a motocross race was positively related to their child crying after a competition. Additionally, achievement orientation and family cohesion were both positively related to having a child celebrate after the race. Results also show that some situational factors have an influence on child behavior over and above the influence of the family environment factors. Specifically, trackside parent hostility significantly predicts crying after a race. This work informs the literature on the degree to which short-term situational contexts may affect child behavior, as well as provides insight into parent-child relationships within the context of motocross.

$1 \begin{aligned} & \text { large body of literature exists that } \\ & \text { examines the influences of } \\ & \text { parenting and contextual factors on }\end{aligned}$ child development (Belsky, 1984; Holt, 2016). Commonly, stable, long-term contextual factors have been shown to be associated with parenting behaviors. This is evident in work by La Placa \& Corlyon (2016) which examined the impact poverty has on parenting behaviors. Comparatively, very little research exists examining the impact short-term situational contexts may 
have on the behavior of children. There has also been very little attention paid to the degree to which pre-existing family environment is related to parenting within short-term situational contexts. Therefore, the current study investigates the effect of parental warmth and hostility on child behavior during a short-term situational context. Family environment is also evaluated to investigate the magnitude of influence each factor has on child's behavior.

\section{Competitive Youth Sports: Parent Behavior}

According to data released by the United States Department of Health and Human Services (2010), 90\% of American youth choose to participate in organized sports throughout their childhood and into adolescence. Parents are often responsible for involving their children in physical activities. Frequently, they act as their first coach, and invest their time, money, and emotional support into their children's success (Downward, Hallmann, \& Pawlowski, 2014; Fredricks \& Eccles, 2005; Snyder \& Spretizer, 1973). Parents invest these resources in part because competitive events allow children to experience success and failure in a controlled context, and offer parents opportunities to help their children learn how to manage success and failure (Partridge, Brustad, Babkes, \& Stellino, 2008). As a result, this creates an interesting context to study how both parent and child behaviors are affected by short-term situational contexts. Short-term situational contexts are events or processes that occur briefly such as moving to a new home, transitioning to a new classroom, or competing in a sports event.

When an athlete performs, they are in a public area, constantly receiving feedback, either verbal or nonverbal from other people (e.g., coaches, spectators, fans) (Fredricks \& Eccles, 2004). The way an athlete copes with the stress brought on by performance can be heavily impacted by their parents (Keegan, Harwood, Spray, \& Lavallee, 2009; Keegan, Spray, Harwood, \& Lavallee, 2010). Pivotal work by Fredricks and Eccles (2004) discusses several ways parents impact their children's beliefs related to their sport's experiences. One of the key roles parents partake in is being the purveyor of emotional support and guidance regarding positive sports participation. This is especially important as the approach parents take regarding this role strongly influences both positively and negatively a child's beliefs and their motivation and performance within the sport (O’Rourke, Smith, Smoll, \& Cumming, 2014).

Often, parents convey support or guidance through their behavior. Children tend to prefer parents who engage in attentive silence during sporting events, which involves sitting down quietly, controlling one's emotions, and maintaining a positive attitude (Knight, Boden, \& Holt, 2010; Omli \& Wiese-Bjornstal, 2011). Further preference is given to parents who 
cheer but do so in an appropriate manner such as smiling and clapping (Omli \& Wiese-Bjornstal, 2011). Research has demonstrated that when parents provide appropriate emotional support and praise during competition they are more likely to have children who indicate higher levels of intrinsic motivation, enjoyment, competence, and coping skills (Knight, Neely, \& Holt, 2011; Power \& Woolger, 1994). As a result, these children are more likely to engage in sport for a longer period of time (Woolger \& Power, 2000). By participating in sports for an extended period, children experience a number of physical and emotional benefits. This can include lower levels of body fat and more finely tuned leadership skills (Kniffin, Wansink, \& Shimizu, 2015; Telford et al., 2016).

Gould, Lauer, Rolo, Jannes, \& Pennisi (2006) note that a large population of parents positively influence their children's athletic development through their behavior. However, their results also highlight the impact that negative parental behavior can have on child development. The authors indicate that these parents have the tendency to overemphasize winning, hold unrealistic expectations of their child's abilities, and are highly critical of their child's performance. Children are more likely to describe negative impacts when a parent engages in arguing (i.e.: Referees, spectators, or other parents), blaming, derogation, or disruption (Omli \& WieseBjornstal, 2011). All of these examples represent harsh behaviors. More recent work highlights that parents who overemphasize winning and are overly critical can cause children to experience higher levels of anxiety, fear of failure, and lower levels of perceived competence (Bois, Lalanne, \& Delforge, 2009; Knight \& Holt, 2014). These negative outcomes have implications for children's mental health and can ultimately cause the child to lose interest in sports performance altogether.

The situational pressure of a competitive event is associated with parent and child behavior; therefore, the current study contributes to this existing research by testing for the association of child behavior with both short-term and long-term family components.

\section{Family Environment: Cohesion, Conflict, and Achievement Orientation}

Family environment has been widely acknowledged as a predictor of child adjustment (Fomby \& Cherlin, 2007; Laurent et al., 2013). A growing body of the literature suggests that families with low cohesion often indicate higher levels of stress and less warm parent-child relationships (Barber and Buehler, 1996, Orthner, Jones-Sanpei, \& Williamson, 2004). Behnke et al (2008) demonstrate that family cohesion strongly affects the relationship between stress and parenting behaviors. The degree to which family environment (including family cohesion) can show similar effects on short-term contextual pressures is relatively unknown. 
However, it may play a pertinent role in a competitive youth sports context.

It has also been established that family level conflict influences parenting behaviors during long-term contextual pressures (Barajas-Gonzalez \& Brooks-Gunn, 2014; Neppl, Senia, \& Donnellan, 2016). For instance, families who have children that suffer from chronic pain indicate higher levels of conflict, and lower levels of cohesion (Palermo, Valrie, Karlson, 2014). Conflict among family members is also commonly associated with parents' behavior towards their children (Strassberg, Dodge, Bates, \& Pettit, 1994; Schwartz et al., 2013), especially hostile parenting (Erel, Margolin, \& John, 1998; Weaver, Shaw, Crossan, Dishion \& Wilson, 2015). Interestingly, very little research has examined the impact that short-term situational factors and conflict have on parental behavior.

The third element of family environment that has been found to be associated with parenting behavior is achievement orientation. Achievement orientation is defined as the extent to which families strive to achieve academic and occupational success (Dweck \& Leggett, 1988; Dietl, Meurs, \& Blickle, 2017). Power \& Woolger (1994) investigated a form of achievement orientation (performance goals) and parenting behaviors during swimming competitions. They found that parental performance goals and directiveness showed curvilinear effects. That is, children reported having the most enthusiasm for swimming when their parents reported moderate levels of performance goals. More recent work within the youth sports literature has continued to examine the relationship between parental performance goals, pressure, and behavior, and its influences on child outcomes (Dorsch, Smith, \& Dotterer, 2015; Holt \& Knight, 2014). Such work has shown that athletes who identify as having perfectionistic parents were more likely to perceive higher levels of parental pressure and suffered from poor adjustment (Randall, Bohnert, \& Travers, 2015). Similar work by O'Rourke et al (2014), noted that high parental pressure during youth sports events was associated with the highest levels of extreme responses for children (e.g., celebration or crying).

\section{Motocross - What is it?}

This research draws from

Bronfenbrenner's bioecological framework (Bronfenbrenner, 1977; Bronfenbrenner \& Morris, 1998). This framework posits that to understand child development researchers must first evaluate the systems that are found within a child's environment. Specifically, this theory suggests that children are affected by different systems in unique ways. Bronfenbrenner's initial work identified four systems: microsystem (e.g., family and peers), mesosystem (e.g., the relationship between parents and child's school), exosystem (e.g., parental job loss), and macrosystem (e.g., law, religion, culture). 
Within the current paper, the authors focus specifically on the microsystem and the mesosystem and child behavior. Specifically, they are interested stable family environment factors within the microsystem (e.g., achievement orientation) and shortterm situational context within the mesosystem (e.g., parental hostility). Parent hostility and warmth is measured at the motocross track to represent the relationship between the parent and the sport of motocross (how the parent behaves specifically at the track) and how this behavior affects the child.

The sport of motocross was especially appropriate to address the hypotheses of this study because of its growing popularity. The term motocross comes from the combination of two words: "Moto" for motorcycles and "cross" for cross-country. Motocross is a sport that can be engaged in as early as four and individuals may choose to continue riding into older age $(60+)$ (AMA, 2017). Motocross involves riding an off-road motorcycle on courses that incorporate hills, dirt roads, muddy tracks, turns, and jumps. Today, motocross is one of the fastest growing sports in the world. This is due in part to corporate sponsorships, and events including the $\mathrm{X}$ Games, Supercross, and the Lucas Oil Pro Motocross Championship. In 2016, more than 7 million people watched professional motocross, with 498,304 living streaming events and 277,280 people physically attending races (NBC Sport Group, 2016). The sport also has a substantial social media following with 370,000 total Instagram followers, 502,000 total Facebook followers and 95,000 total Twitter followers (NBC Sport Group, 2016).

\section{Summary}

Within the current study, the authors hypothesize that parents who display positive behavior in the form of warmth will have children who are more likely to celebrate after a race. Conversely, the authors hypothesize that parents who display negative behavior in the form of hostility will have children who cry or display anger before a race. The authors also hypothesize that families with higher levels of cohesion will demonstrate more warmth at a competitive motocross event. Additionally, families with higher levels of conflict will demonstrate more hostility towards their children before the race. Finally, the authors hypothesize that the short-term situational context (parent behavior prior to a race) will influence child behavior following a race after controlling for the influence of family environment.

\section{Method}

\section{Participants}

The sample consisted of 33 parents of children who were active participants in motocross. Parents were asked to report how many years, on average, they had been involved in the sport of motocross $(M=$ 14.03 years, $S D=7.72)$. However, there was a large amount of variation in years of experience ranging from 1-44 years. Parents 
also indicated how far they traveled for their child to compete. Three percent of parents reported traveling less than an hour, 12\% reported traveling one to two hours, $12 \%$ reported traveling two to three hours, and $72 \%$ indicated having traveled three to four hours. Questions regarding motocross expenses were also asked. Sixty percent of parents indicated having spent more than $\$ 3,000$ over the course of the last three months on motocross related expense.

\section{Procedure}

Recruitment occurred during several Super Series races held at a professional motocross track. The races were designed for non-professional or amateur athletes from Limited Peewee Jr. Class (4-6 years) to Senior Class (60+). Participants were recruited through convenience sampling. Throughout each race day, a booth was available for parents to approach and complete a survey on their family dynamics and motocross experiences. A majority of youth riders at these races had a parent participate in the study. Parents were asked to provide informed consent and were then invited to provide basic demographic information regarding their involvement in motocross (i.e. expenses, time, and years of experience). Additional questions included measures of child behavior after races, trackside parent behavior before and after races, and overall family environment. In exchange for their participation, respondents received racing decals.

\section{Measures}

Descriptives. Parents were asked to complete investigator created demographic questions related to their family's motocross experiences. These quantitative and qualitative questions included how much money they spent, reasons for participating in the sport, how they treat their children after a race, how old their child is, etc. To provide characteristics of the sample, participants were asked about monetary investment, age of the child, how often they discuss the sport at home, how long the family has been involved in motocross and how far they travelled to get to the event. Monetary investment was measured by participant response to a five-point scale of ranges of income (i.e.: $1=\$ 0-\$ 500,2=$ $\$ 500-\$ 1000,5=\$ 3,000+)$. Each participant reported the age of their child participating in the races. If a parent reported on more than one child who was participating in the race $(N=3)$ the average of their ages was calculated and included in descriptive analyses $(M=14.03, S D=7.72)$. Parents also reported how often they discuss motocross outside of the track on a scale ranging from never (0) to always (3). Finally, the parent reported the number years and months they had been involved in motocross. From these results, the number of months was calculated and reported. Descriptive statistics are shown in Table 1.

Stable family environment factors. Parents completed three subscales of the 
Family Environment Scale (FES: Moos \& Moos, 1994). This scale assesses the perceived social climate of an individual's family and can be taken by any member of the family (Moos, 1974). This scale is comprised of three systemic constructs relating to the family. These constructs include Relationship, Personal Growth, and Systems Maintenance. The first subscale came from the Personal Growth dimension of the FES: Achievement Orientation (the degree to which activities are competitive). The second and third subscales used in this analysis were taken from the Relationships dimension of the FES: Conflict (the degree to which anger and conflict are openly expressed among family members) and Cohesion (the amount family members provide commitment and support to one another).

Internal consistency of the scale has been reported as ranging from .61 to .78, and test-retest reliability ranging from .61 to .78 (Moos, 1994). The full instrument consists of three forms: Real, Ideal, and Expectations. Because the current study sought to investigate perceptions of the home environment, the Real form was used. Answers were given on a four-point scale ranging from not true (0) to true (3). The three scales were cohesion ( 9 items, $\alpha=$ 0.78 ), conflict (7 items, $\alpha=0.68)$, and achievement orientation (7 items, $\alpha=0.63$ ). Two items were dropped from both the conflict and achievement-orientation scales because their item-total correlations were less than 20 .
Situational stressor reaction. Parents completing the survey reported on the trackside parent's behaviors toward the child both before and after the race using the Behavioral Affect Rating Scale (BARS: Conger, 1989). This scale has been used extensively to explore parenting behaviors (Schofield, Conger, Gonzales, \& Merrick, 2016; Wetzel \& Robins, 2016) and is a 22item scale that assesses warmth and hostility within a close relationship. In the current study, the parent reports on the trackside parent's behavior toward the racing child. The wording of the scale was slightly adapted to be specific to the short-term situational context of the motocross event. Additionally, the current study utilizes an abbreviated 11-item scale to include only questions that were pertinent to the context. Items were answered on a seven-point scale from never (0) to always (6). The parental hostility (five items, $\alpha=.68$ ) aspect reflects how frequently a parent behaves in a hostile nature towards their child. Sample items include "before a race, how often does the trackside parent get angry at your child?" and "before a race, how often does the trackside parent shout or yell at your child?". One item, "parent hits, pushes, grabs, or shoves your child" was dropped from the hostility scale because the itemtotal correlation fell below .20 and because the purpose of this study was to focus on hostility rather than physical abuse. The parental warmth aspect (five items, $\alpha=.80$ ) assesses how often a parent displays warmth towards their child. Sample items included 
"before a race, how often does the trackside parent act loving and affectionate toward your child?" and "before a race, how often does the trackside parent help your child do something that is important to your child?"

Child behavior. As there is little research involving the sport of motocross, the questions related to child's behavior after the race were created by the principal investigator. Parents reported on each of three specific behaviors after a race (i.e., celebrates, cries, gets angry). Each item was answered on a four-point scale from never (0) to always (3). Items read "how often does your child celebrate after the race?", "how often does your child get angry after the race?", and "how often does your child cry after the race?"

\section{Statistical Analysis}

SPSS Statistics 21 software was used to analyze these data. Descriptive statistics were analyzed to determine parental investment in the sport of motocross (e.g. distance traveled, financial investment), experience, and family environment. Correlations analyses were conducted to identify the relationship between parent behavior, family environment, and child response after the race. Further, regression analyses were conducted to test the unique contribution of the family environment and motocross contexts to each of the dependent variables (crying, celebrating, and anger) by the family

\section{Results}

Correlation analysis and multiple regression analyses were performed to address the study purposes. Table 2 contains the bivariate correlations among all variables used in the preliminary analyses. In testing hypothesis one, the first part regarding warmth and celebrating after the race was not supported. However, the second part of hypothesis one was partially supported in that, while there was no significant finding regarding anger after a race, parents who display hostility before the race will have children that cry after the race $(r=0.42, p \leq 0.05)$. The second hypothesis was not supported at the bivariate level. Indeed, families with higher levels of cohesion and conflict, were not shown to exhibit more warmth or hostility before a competitive event. Additional family environment variables, however, were correlated with child behaviors after the race. Specifically, both achievement orientation $(r=0.52)$ and family cohesion $(r$ $=0.34)$ were significantly correlated with their child celebrating after the race. The remaining family environment variable, family conflict, was only correlated with family cohesion $(r=0.54)$. Of the two parent behaviors at the race, trackside parent hostility was associated with child behavior after the race. Specifically, hostility before the race was associated with their child crying after the race $(r=0.42)$. Overall, the pattern of associations was consistent with expectations, justifying formal tests of study hypotheses. However, because there were no significant 
correlations between the independent variables and the child getting angry after the race, this variable was dropped future analyses.

The remaining hypotheses were that the dimensions of the situational context would predict child behavior after a race over and above the stable family environment factors. Separate models were run for each dependent variable due to the modest sample size. For each outcome (crying and celebrating after the race), family environment factors were entered into the analysis to assess the influence of these variables on each of the outcome variables. Next, the situational context behaviors (hostility and warmth) were added to see the effect of these two behaviors beyond the effect of the stable family environment factors. For example, the first model (Table 3) shows the effects of family achievement orientation, family conflict, and family cohesion on crying after a race. Then (also in Table 1) trackside parent hostility and warmth were added to the model. In Model 1 predicting crying after the race (Table 4) family achievement orientation remained a significant factor in influencing celebratory behavior after a race $(\beta=1.10, p \leq 0.01)$ after taking the other three family factors into account, however, the association between family cohesion and crying after the race receded. Regarding the final hypothesis, hostility and warmth (Model 2 in Table 4) from the trackside parent did not have an influence on the child's behavior after the race. However, after including parent situational behavior in the model, family conflict was negatively associated with celebration after the race $(\beta=-0.37, p \leq$ 0.05).

Further testing the final hypothesis, table one shows the regression model results for a child crying after a race. In the first model, the stable family environment factors did not predict the behavior of the child after the race. However, hostility from the trackside parent did significantly predict this behavior over and above any influence from the stable family environments $(\beta=$ $0.50, p \leq 0.05)$.

\section{Discussion}

The first hypothesis examines how levels of warmth and hostility exhibited by the trackside parent during an acute situational stressor - a motocross event influence child behavior after a race. Our hypothesis was partially supported in that high observed hostility from the trackside parent at a race influenced high occurrence of crying after a race from the child. This is consistent with literature showing that high levels of negative interactions (such as a child experiencing hostility from their parent) has been shown to influence depression and anxiety (Randall, Bohnert, \& Travers, 2015). This can lead to poor emotional regulation (Keenan, 2000) after a race and result in a child crying. Displayed warmth from the trackside parent, on the other hand, did not significantly relate to any of the outcome variables. 
The second hypothesis was not supported. Higher levels of cohesion and conflict were not associated with warmth or hostility at an event. This could be due to the majority of the current literature focusing on long-term contextual pressures rather than acute, short-term stressors. Long-term family behaviors may not be associated to short-term family behaviors in a high stress environment.

Finally, consistent with our final hypothesis, hostility exhibited by the trackside parent influenced the child crying after a race over and above any influence of stable family environment factors. However, with regard to celebrating after the race, the stable family environment factors had more of an influence on the child's behavior after the race than the behavior of the parent during the acute stressor of the motocross event. Specifically, family conflict and achievement orientation influenced the child celebrating after the race. This finding is contrary to the idea that parents who highly prioritize achievement orientation may respond poorly when their child does not achieve however, in the dangerous sport of motocross, a child simply finishing a race may be considered an achievement especially considering the average age of participants. On the other hand, when the trackside parent expressed hostile behaviors it predicted how often the child cried after the race. These findings are consistent with the association between social support and higher functioning during times of stress (Cohen, 2004). This is contrary to previous literature supporting the protective effect of family cohesion on chronic stressors (Farrell, Barnes, \& Banerjee, 1995; Harris \& Molock, 2000; Mossakowski \& Zhang, 2014). However, the current study builds on previous work by showing the strong effect of parent hostility during acute situational stressors. Although the expected association between family conflict and hostility was not found, this may have been due to the public setting. When in public spaces, an angry or frustrated parent can react without drawing attention to themselves more easily by reducing their warmth than by increasing their hostility. Consistent with this possibility was the finding that the item on the BARS scale measuring physical aggression by the parent did not load highly onto the scale in this sample. Certainly, in private settings higher levels of conflict are associated with harsh and abusive behavior (McCullough et al., 1998).

The findings of this study have implications for parents/caregivers. These results can be used to create a webinar designed to help educate parents in regard to how to how their behaviors affect their children during a competitive motocross event, and the best ways to manage these behaviors. As many parents are also coaches within this sport, an intervention using these results could help build communication skills between parents and children that could influence the levels of stress and frustration experienced by both parties. Further research is necessary to identify what parts of motocross 
competition (preparation, starting line, finish line, etc.) cause the most stress and frustration between parents and their children. Webinar tools can then be designed to help facilitate the conversations that parents and children struggle with the most.

These findings also have implications for the governing body of this sport, its officials, referees, and promoters. These results highlight the important role that parents play in their child's experience of the sport. By also having an understanding of this, these individuals can help parents and children navigate the world of motocross while at the track. This ensures that all parties are engaging in the sport in both a safe and enjoyable manner.

A limitation of this study is its modest sample size, as it affects the statistical power. However, we were encouraged to see the hypothesized effects were large enough to be detected notwithstanding this limitation. Although we had a high rate of participation from parents attending the races, this was a sample of convenience, which limits generalizability. The analyses were based on information from a single reporter, which may have inflated associations between variables. Despite these limitations, this study provides support for the role of family environment and parental behavior during a short-term situation stressor in predicting child behavior. Indeed, this study provides unique insight into a previously understudied sport. In most cases, the parent who completed the survey was not the parent who was with their child trackside, likely indicating they were not the parent who spent the most time with their child trackside. Future research is needed to replicate and extend these findings to other situational stressors. Further, testing mediation in these contexts would be a beneficial additional to existing research.

\section{Conclusion}

In conclusion, the results of this study are valuable in expanding upon previous research examining the impact of parenting behaviors and family environment within two contexts, both at home and at a motocross event. This work provides a snapshot of how parenting behaviors can influence child outcomes in amateur motocross racing. This is especially relevant as the sport continues to rise in popularity. It informs the literature on the degree to which short-term situational contexts may affect parenting by illustrating the relationship between parent and child behaviors at a race. It also elucidates how deeply affected children can be by their parent's behaviors. 


\section{References}

American Motocross Association. (2017). AMA Racing 2017 Rule Book. [Ereader Version] Retrieved from https://www.americanmotorcyclist.c om/Racing/Story/motocross-rules-1 Barajas-Gonzalez, R. G., \& Brooks-Gunn, J. (2014). Income, neighborhood stressors, and harsh parenting: Test of moderation by ethnicity, age, and gender. Journal of family psychology, 28(6), 855.

Barber, B. K., \& Buehler, C. (1996). Family cohesion and enmeshment: Different constructs, different effects. Journal of Marriage and the Family, 58(2), 433441.

Behnke, A. O., MacDermid, S. M., Coltrane, S. L., Parke, R. D., Duffy, S., \& Widaman, K. F. (2008). Family cohesion in the lives of Mexican American and European American parents. Journal of Marriage and Family, 70(4), 1045-1059.

Belsky, J. (1984). The determinants of parenting: A process model. Child development, 55(1), 83-96.

Bois, J. E., Lalanne, J., \& Delforge, C. (2009). The influence of parenting practices and parental presence on children's and adolescents' precompetitive anxiety. Journal of Sports Sciences, 27(10), 995-1005.

Bronfenbrenner, U. (1977). Toward an experimental ecology of human development. American Psychologist, 32, 513-531.
Bronfenbrenner, U. \& Morris, P. A. (1998). The ecology of developmental processes. In W. Damon \& R. M. Lerner (Eds.), Handbook of child psychology, Vol. 1: Theoretical models of buman development (5th ed., pp. 9931023). New York: John Wiley and Sons, Inc.

Cohen, S. (2004). Social relationships and health. American Psychologist, 59, 676684.

Conger, R. D. (1989). Behavioral Affect Rating Scale (BARS): Spousal rating of hostility and warmth: Iowa Youth and Families Project. Ames, IA: Iowa State University.

Dietl, E., Meurs, J. A., \& Blickle, G. (2017). Do they know how hard I work? Investigating how implicit/explicit achievement orientation, reputation, and political skill affect occupational status. European Journal of Work and Organizational Psychology, 26(1), 120132.

Dorsch, T. E., Smith, A. L., Wilson, S. R., \& McDonough, M. H. (2015). Parent goals and verbal sideline behavior in organized youth sport. Sport, Exercise, and Performance Psychology, 4(1), 19.

Downward, P., Hallmann, K., \& Pawlowski, T. (2014). Assessing parental impact on the sports participation of children: A socio-economic analysis of the UK. European journal of sport science, 14(1), 84-90.

Dweck, Carol S.; Leggett, Ellen L. (1988). A social-cognitive approach to 
motivation and personality.

Psychological Review, 95(2), 256-273.

Erel, O., Margolin, G., \& John, R.S., (1998).

Observed sibling interaction: Links

with the martial and mother-child relationship. Developmental Psychology, 34, 288-298.

Farrell, M. P., Barnes, G. M., \& Banerjee, S. (1995). Family cohesion as a buffer against the effects of problemdrinking fathers on psychological distress, deviant behavior, and heavy drinking in adolescents. Journal of bealth and social behavior, 36(4), 377 385.

Fredricks, J. A., \& Eccles, J. S. (2004). Parental influences on youth involvement in sports. In M. R. Weiss (Ed.), Developmental sport and exercise psychology: A lifespan perspective (pp. 145-164). Morgantown, WV: Fitness Information Technology.

Fredricks, J. A., \& Eccles, J. S. (2005). Family socialization, gender, and sport motivation and involvement. Journal of Sport \& Exercise Psychology, 27, 3-31.

Fomby, P., \& Cherlin, A. J. (2007). Family instability and child well-being. American sociological review, 72(2), 181 204.

Gould, D., Lauer, L., Rolo, C., Jannes, C., \& Pennisi, N. (2006). Understanding the role parents play in tennis success: a national survey of junior tennis coaches. British journal of sports medicine, 40(7), 632-636.
Harris, T. L., \& Molock, S. D. (2000). Cultural orientation, family cohesion, and family support in suicide ideation and depression among African American college students. Suicide and Life-Threatening Behavior, 30(4), 341 353.

Holt, N. L. (2016). Positive youth development through sport. New York, New York. Routledge.

Holt, N. L., \& Knight, C. J. (2014). Parenting in youth sport: From research to practice.

New York, New York. Routledge

Keegan, R. J., Harwood, C. G., Spray, C. M., \& Lavallee, D. E. (2009). A qualitative investigation exploring the motivational climate in early career sports participants: Coach, parent and peer influences on sport motivation. Psychology of sport and exercise, 10(3), 361-372.

Keegan, R., Spray, C., Harwood, C., \& Lavallee, D. (2010). The motivational atmosphere in youth sport: Coach, parent, and peer influences on motivation in specializing sport participants. Journal of applied sport psychology, 22(1), 87-105.

Keenan, K. (2000). Emotion dysregulation as a risk factor for child psychopathology. Clinical Psychology: Science and Practice, 7, 418-434.

Kniffin, K. M., Wansink, B., \& Shimizu, M. (2015). Sports at work: anticipated and persistent correlates of participation in high school athletics. 
Journal of Leadership \& Organizational Studies, 22(2), 217-230.

Knight, C. J., Neely, K. C., \& Holt, N. L. (2011). Parental behaviors in team sports: How do female athletes want parents to behave? Journal of Applied Sport Psychology, 23, 76-92. doi:10.1080/10413200.2010.525589

Knight, C. J., \& Holt, N. L. (2014).

Parenting in youth tennis:

Understanding and enhancing children's experiences. Psychology of Sport and Exercise, 15(2), 155-164.

Knight, C. J., Boden, C. M., \& Holt, N. L. (2010). Junior tennis players' preferences for parental behaviors. Journal of applied sport psychology, 22(4), 377-391.

U.S. Department of Health and Human Services. (2010). Morbidity and mortality report (Vol. 59, No. SS-5). Atlanta, GA: U.S. Department of Health and Human Services, National Center for Chronic Disease Prevention and Health Promotion. Retrieved from: www.cdc.gov/mmwr/pdf/ss/ss5905. pdf

La Placa, V., \& Corlyon, J. (2016). Unpacking the relationship between parenting and poverty: Theory, evidence and policy. Social Policy and Society, 15(01), 11-28.

Laurent, H. K., Leve, L. D., Neiderhiser, J. M., Natsuaki, M. N., Shaw, D. S., Fisher, P. A., ... \& Reiss, D. (2013). Effects of Parental Depressive
Symptoms on Child Adjustment Moderated by Hypothalamic Pituitary Adrenal Activity: Within-and Between-Family Risk. Child development, 84(2), 528-542.

McCullough, M., \& Scherman, A. (1998). Family-of-origin interaction and adolescent mothers' potential for child abuse. Adolescence, 31 (3), 145154.

Moos, R. H. (1974). Family Environment Scale preliminary manual. Palo Alto, CA: Consulting Psychologist Press.

Moos, R. H., \& Moos, B. S. (1994). Family environment scale manual. Mind Garden, CA. Consulting Psychologists Press.

Mossakowski, K. N., \& Zhang, W. (2014). Does social support buffer the stress of discrimination and reduce psychological distress among Asian Americans? Social Psychology Quarterly, 0190272514534271.

Neppl, T. K., Senia, J. M., \& Donnellan, M. B. (2016). Effects of economic hardship: Testing the family stress model over time. Journal of Family Psychology, 30(1), 12.

Omli, J., \& Wiese-Bjornstal, D. M. (2011). Kids speak: Preferred parental behavior at youth sport events. Research quarterly for exercise and sport, 82(4), 702-711.

Orthner, D. K., Jones-Sanpei, H., \& Williamson, S. (2004). The resilience and strengths of low-income families. Family relations, 53(2), 159-167. 
O’Rourke, D. J., Smith, R. E., Smoll, F. L., \& Cumming, S. P. (2014). Relations of parent-and coach-initiated motivational climates to young athletes' self-esteem, performance anxiety, and autonomous motivation: who is more influential? Journal of Applied Sport Psychology, 26(4), 395408.

Partridge, J. A., Brustad, R. J., \& Babkes Stellino, M. (2008). Social influence in sport. Advances in Sport Psychology, 3, 269-291.

Randall, E. T., Bohnert, A. M., \& Travers, L. V. (2015). Understanding affluent adolescent adjustment: The interplay of parental perfectionism, perceived parental pressure, and organized activity involvement. Journal of adolescence, 41, 56-66.

Palermo, T. M., Valrie, C. R., \& Karlson, C. W. (2014). Family and parent influences on pediatric chronic pain: a developmental perspective. American Psychologist, 69(2), 142.

Power, T. G., \& Woolger, C. (1994). Parenting practices and age-group swimming: A correlational study. Research quarterly for exercise and sport, 65(1), 59-66.

Salzinger, S., Feldman, R. S., Ng-Mak, D. S., Mojica, E., Stockhammer, T., \& Rosario, M. (2002). Effects of partner violence and physical child abuse on child behavior: A study of abused and comparison children. Journal of Family Violence, 17(1), 23-52.
Schofield, T. J., Conger, R. D., Gonzales, J. E., \& Merrick, M. T. (2016). Harsh parenting, physical health, and the protective role of positive parentadolescent relationships. Social Science \& Medicine, 157, 18-26.

Schwartz, D., Lansford, J. E., Dodge, K. A., Pettit, G. S., \& Bates, J. E. (2013). The link between harsh home environments and negative academic trajectories is exacerbated by victimization in the elementary school peer group. Developmental Psychology, 49 (2), 305.

Snyder, E. E., \& Spreitzer, E. A. (1973). Family influence and involvement in sports. Research Quarterly. American Association for Health, Physical Education, and Recreation, 44(3), 249255.

NBC Sport Group. (2016). Lucas Oil ProMotocross Championship 2016 Season Recap. Retrieved from: 2016 Lucas Oil Pro Motocross Championship End of Compressed.pdf

Strassberg, Z., Dodge, K.A., Pettit, G.S., \& Bates, J.E., (1994). Spanking in the home and children's subsequent aggression toward kindergarten peers. Development and Psychopathology, 6, 445461.

Telford, R. M., Telford, R. D., Cochrane, T., Cunningham, R. B., Olive, L. S., \& Davey, R. (2016). The influence of sport club participation on physical activity, fitness and body fat during childhood and adolescence: the 
LOOK Longitudinal Study. Journal of science and medicine in sport, 19(5), 400406.

Weaver, C. M., Shaw, D. S., Crossan, J. L., Dishion, T. J., \& Wilson, M. N. (2015). Parent-child conflict and early childhood adjustment in twoparent low-income families: Parallel developmental processes. Child Psychiatry \& Human Development, 46(1), 94-107.

Wetzel, E., \& Robins, R. W. (2016). Are parenting practices associated with the development of narcissism? Findings from a longitudinal study of Mexican origin youth. Journal of Research in Personality, 63, 84-94.

Woolger, C., \& Power, T. G. (2000). Parenting and children's intrinsic motivation in age group swimming. Journal of Applied Developmental Psychology, 21(6), 595-607. 
Table 1

\section{Tables}

Descriptive Statistics of Sample

\begin{tabular}{lccc}
\hline & $\underline{\text { Range }}$ & $\underline{M}$ & $\underline{S D}$ \\
Months participating in motocross & $13-531$ & 217.03 & 168.35 \\
Cost & $0-4$ & 2.84 & 1.25 \\
Traveled & $0-4$ & 2.53 & 0.84 \\
Talk about at home & $2-3$ & 2.52 & 0.51 \\
Child Age & $4-33$ & 14.03 & 7.72 \\
Family Factors & & & \\
$\quad$ Achieve & $0.89-2.44$ & 1.64 & 0.33 \\
$\quad$ Conflict & $0-2$ & 0.83 & 0.41 \\
$\quad$ Cohesion & $1.56-3$ & 2.39 & 0.41 \\
Situational Stressor Reaction & & & \\
$\quad$ Parent Warmth & $1.6-6.8$ & 5.08 & 1.01 \\
$\quad$ Parent Hostility & $0-3.17$ & 1.05 & 0.84 \\
Child Behaviors & & & \\
$\quad$ Child celebrates after the race & $0-3$ & 1.7 & 0.85 \\
$\quad$ Child gets angry after the race & $0-2$ & 0.82 & 0.53 \\
$\quad$ Child cries after the race & $0-2$ & 0.48 & 0.62 \\
\hline
\end{tabular}


Table 2

Correlations Among Variables Used in Analyses

1

\begin{tabular}{lllllll}
2 & 3 & 4 & 5 & 6 & 7 & 8 \\
\hline
\end{tabular}

1. Family achievement orientation

2. Family conflict

$-.10$

3. Family cohesion $.31-.54^{* *}-$

4. Parent hostility $\begin{array}{lll}.00 & .26 & -.20\end{array}$

5. Parent warmth $\begin{array}{lllll}.18 & -.10 & .01 & -.40^{*} & -\end{array}$

6. Child celebrates after racing $\begin{array}{lll}.52^{* *} & -.30 & .34^{* *}\end{array}$

7. Child gets angry after racing $\begin{array}{lll}.18 & .14 & .02\end{array}$

8. Child cries after racing $.00 \quad .01$

$\begin{array}{lll}.02 & .17 & .17\end{array}$

$\begin{array}{lll}.00 & .42^{*} & -.10\end{array}$

.22

Note. ${ }^{*} p \leq .05,{ }^{* *} p \leq .01$ 
Table 3

Summary of Hierarcbical Regression Analysis for V ariables Predicting Crying after a Race

\begin{tabular}{llllllll}
\hline & \multicolumn{3}{c}{ Model 1 } & \multicolumn{3}{c}{ Model 2 } \\
& $B$ & SE B & $\beta$ & $B$ & SE B & $\beta$ \\
\hline Stable Family Environment & & & & & & \\
$\quad$ Factors & & & & & & \\
$\quad$ Achievement Orientation & -0.12 & 0.37 & -0.07 & -0.19 & 0.35 & -0.10 \\
$\quad$ Conflict & -0.11 & 0.37 & -0.07 & 0.023 & 0.34 & -0.15 \\
$\quad$ Cohesion & -0.02 & 0.36 & -0.01 & 0.07 & 0.33 & 0.05 \\
$\quad$ Situation Stressor Reaction & & & & & & \\
$\quad$ Parent Hostility & & & & 0.38 & 0.15 & $0.50^{*}$ \\
$\quad$ Parent Warmth & & & & 0.11 & 0.12 & 0.17 \\
\hline
\end{tabular}

Note: ${ }^{*} p \leq .05$ 
Table 4

Summary of Hierarchical Regression Analysis for V ariables Predicting Celebration after a Race

\begin{tabular}{|c|c|c|c|c|c|c|}
\hline & \multicolumn{3}{|c|}{ Model 1} & \multicolumn{3}{|c|}{ Model 2} \\
\hline & $B$ & SEB & $\beta$ & $B$ & SE B & $\beta$ \\
\hline \multicolumn{7}{|l|}{ Stable Family Environment } \\
\hline \multicolumn{7}{|l|}{ Factors } \\
\hline Achievement Orientation & 1.10 & 0.41 & $0.43^{*}$ & 1.01 & 0.39 & $\begin{array}{l}0.39 \\
*\end{array}$ \\
\hline Conflict & -0.68 & 0.40 & -0.31 & -0.81 & 0.37 & $\begin{array}{l}- \\
0.37 \\
*\end{array}$ \\
\hline Cohesion & 0.15 & 0.39 & 0.74 & 0.24 & 0.36 & 0.12 \\
\hline $\begin{array}{l}\text { Situational Stressor } \\
\text { Reaction }\end{array}$ & & & & & & \\
\hline Parent Hostility & & & & 0.42 & 0.16 & 0.41 \\
\hline Parent Warmth & & & & 0.15 & 0.13 & 0.17 \\
\hline
\end{tabular}

Note: ${ }^{*} p \leq .05$ 